Gut and Liver, Vol. 9, No. 5, September 2015, pp. 657-664

\title{
Hepatitis B Surface Antigen Quantification across Different Phases of Chronic Hepatitis B Virus Infection Using an Immunoradiometric Assay
}

Kwang Hyun Chung*, Won Kim ${ }^{\dagger}$, Byeong Gwan Kim ${ }^{\dagger}$, Ho-Young Lee ${ }^{\ddagger}$, Eunhyo Jin*, Yuri Cho*, Ji Yeon Seo*, Hwi Young Kim ${ }^{\dagger}$, Yong Jin Jung ${ }^{\dagger}$, Ji Won Kim ${ }^{\dagger}$, Ji Bong Jeong ${ }^{\dagger}$, and Kook Lae Lee ${ }^{\dagger}$

${ }^{*}$ Department of Internal Medicine and Liver Research Institute, Seoul National University College of Medicine, ${ }^{\dagger}$ Department of Internal Medicine, Seoul Metropolitan Government Seoul National University Boramae Medical Center, Seoul, and ${ }^{\ddagger}$ Department of Nuclear Medicine, Seoul National University Bundang Hospital, Seongnam, Korea

Background/Aims: Quantification of hepatitis B surface antigen (HBsAg) is an emerging serologic test and may be useful for identifying treatment strategies for chronic hepatitis $B(C H B)$. This study aimed to evaluate HBsAg titers during the natural course of $\mathrm{CHB}$ and identify correlations between HBsAg titers and hepatitis B virus (HBV) DNA concentrations across different $\mathrm{CHB}$ phases measured using an immunoradiometric assay (IRMA). Methods: CHB phases were defined on the basis of HBV DNA concentrations, the presence of hepatitis $\mathrm{B}$ e antigen/antibody ( $\mathrm{HBeAg} / \mathrm{Ab})$ and serum alanine aminotransferase levels. Serum HBsAg titers and paired HBV DNA concentrations in the different phases of CHB were compared using 627 serum samples. Results: Mean HBsAg titers were significantly higher in the immunotolerant (IT) phase and immunoreactive (IR) HBeAg-positive phase than in the low-replicative (LR) and HBeAg-negative CHB (ENH) states. The correlation between HBsAg titers and HBV DNA concentrations was modest in the IT ( $n=36, r=0.804$, $p<0.001)$ and $I R(n=48, r=0.773, p<0.001)$ phases, and it was poor in the LR state $(n=116, r=0.289, p=0.002)$; however, no significant correlation was observed in the ENH state $(n=67, r=0.146, p=0.237)$ or in the oral nucleos(t)ide analogue-treated group ( $n=267$ ). Conclusions: HBsAg quantification using IRMA might be useful for discriminating different CHB phases and different stages of chronic liver disease. (Gut Liver 2015;9:657-664)

Key Words: Hepatitis B virus; Hepatitis B surface antigens; Immunoradiometric assay; DNA

\section{INTRODUCTION}

Chronic hepatitis B (CHB) is an infectious, inflammatory illness of the liver caused by the family Hepadnaviridae, genus Orthohepadnavirus, species Hepatitis B virus (HBV), which is a major global health problem and is responsible for liver cirrhosis, hepatocellular carcinoma (HCC), and related deaths. Currently, over 500,000 to $1,000,000$ deaths per year occur worldwide because of CHB and its associated complications. ${ }^{1,2}$ In principle, the main treatment strategies for CHB consist of suppressing active HBV DNA replication and reducing HBV-related complications. ${ }^{3}$ With the advent of oral nucleos(t)ide analogues (NUCs), $\mathrm{HBV}$ replication can be effectively suppressed, ${ }^{4,5}$ and serum HBV DNA concentrations have been a surrogate marker for HBV replication during antiviral therapy. However, the ultimate goal of CHB treatment is the loss of hepatitis B surface antigen (HBsAg) with the development of hepatitis B surface antibody (anti-HBs), which is associated with favorable clinical outcomes. ${ }^{6,7}$

HBsAg quantification is now methodologically feasible, and might be useful for predicting clinical outcomes in patients with CHB. Previous studies have suggested that HBsAg titers in the sera might reflect the amount of covalently closed circular DNA (cccDNA) in infected hepatocytes. ${ }^{8,9} \mathrm{HBsAg}$ quantification might be crucial for monitoring antiviral treatment responses and determining the optimal time to stop antiviral therapy. ${ }^{10,11}$ Several studies have investigated the correlation between serum HBsAg titers and HBV DNA concentrations. ${ }^{12,13}$ However, the relevance of serum HBsAg quantification and its clinical utility have not been fully evaluated to date.

\footnotetext{
Correspondence to: Won Kim

Department of Internal Medicine, Seoul Metropolitan Government Seoul National University Boramae Medical Center, 20 Boramae-ro 5-gil, Dongjak-gu, Seoul 156-707, Korea

Tel: +82-2-870-2233, Fax: +82-2-831-2826, E-mail: drwon1@snu.ac.kr
}

Received on May 13, 2014. Revised on July 15, 2014. Accepted on August 29, 2014. Published online February 26, 2015

pISSN 1976-2283 eISSN 2005-1212 http://dx.doi.org/10.5009/gnl14188

This article was presented as a poster at the Annual Meeting of the American Association for the Study of Liver Diseases (AASLD) in Boston, November 9-13, 2012.

@ This is an Open Access article distributed under the terms of the Creative Commons Attribution Non-Commercial License (http://creativecommons.org/licenses/by-nc/4.0) which permits unrestricted non-commercial use, distribution, and reproduction in any medium, provided the original work is properly cited. 
HBsAg titers are usually determined on the basis of a complex interplay between HBV and the host immune system. It is important to understand the variations of HBsAg titers across different phases of CHB in accordance with HBV DNA concentrations. ${ }^{14}$ Moreover, recent studies have shown a significant correlation between HBsAg titers and HBV DNA concentrations across different phases of $\mathrm{CHB} .{ }^{15-18}$ However, these studies showed conflicting results regarding these correlations, mainly involved treatment-naive patients, and used chemiluminescent microparticle immunoassay (CMIA). In the present study, a new diagnostic tool employing the immunoradiometric assay (IRMA) method has been used for serum HBsAg quantification. The diagnostic performance of the IRMA method for determining HBsAg titers can be compared with that of the CMIA method. ${ }^{19,20}$ Furthermore, IRMA has several advantages over previous diagnostic tools such as Architect ${ }^{\circledR}$ (Abbott Diagnostics, Abbott Park, IL, USA) and Elecsys ${ }^{\circledR}$ HBsAg II assay (Roche Diagnostics $\mathrm{GmbH}$, Mannheim, Germany). ${ }^{21}$ First, no additional calibrating system is needed for IRMA unlike CMIA, since IRMA utilizes a common automatic gamma counter to measure HBsAg titers in the sera. Second, the IRMA method used in this study is expected to provide diagnostic accuracies similar to the CMIA method, at a lower cost. The aims of this study were to evaluate dynamic changes in HBsAg titers during the natural course of $\mathrm{CHB}$ infection, and to identify correlations across different phases of $\mathrm{CHB}$ between HBsAg titers measured using IRMA and HBV DNA concentrations.

\section{MATERIALS AND METHODS}

\section{Study population and study measurement}

A total of 866 consecutive $\mathrm{HBsAg}$ quantification tests were performed for 785 patients over 18 years of age, who tested HBsAg-positive in the qualitative tests, at the Seoul Metropolitan Government Seoul National University Boramae Medical Center from August 2010 to March 2011. Of these, 174 test results could not match appropriate DNA pairs, and were excluded from analysis. Of the remaining 692 tests, 65 samples were excluded because of the following reasons: (1) 24 samples showed undetectable levels of HBsAg $(<0.1 \mathrm{IU} / \mathrm{mL})$, (2) 17 patients suffered from other malignancies, but not HCC, (3) nine had missing data on hepatitis B e antigen ( $\mathrm{HBeAg}$ ) and/or hepatitis B e antibody (anti-HBe) status, (4) 13 had missing data on liver imaging or liver function test results, and (5) two were coinfected with hepatitis $\mathrm{C}$ virus.

Accordingly, patient demographics, liver biochemistry, qualitative $\mathrm{HBeAg} / \mathrm{anti}-\mathrm{HBe}$ status, clinical evidence of liver cirrhosis (thrombocytopenia, splenomegaly, ascites, and varix), and radiologic evidence of HCC on dynamic computed tomography were retrospectively reviewed. The study protocol was approved by the Institutional Review Board (IRB) of Seoul Metropolitan Government Seoul National University Boramae Medical Center
(IRB number: 06-2011-119) and was conformed to the ethical guidelines of the 1975 Declaration of Helsinki. Informed consent was waived by the IRB.

\section{Definition of different phases of CHB and different treat- ment outcome groups}

The different phases of $\mathrm{CHB}$ in treatment-naive patients were classified according to the serum HBeAg/anti-HBe status, HBV DNA concentrations, and serum alanine aminotransferase (ALT) levels, based on the recent updated guidelines of the European Association for the Study of the Liver (EASL). ${ }^{22}$ The immune tolerant phase (IT) was defined as HBeAg positivity, high levels of serum HBV DNA ( $>10,000 \mathrm{IU} / \mathrm{mL})$, and normal ALT levels $(\leq 40 \mathrm{IU} / \mathrm{L})$. The immune reactive HBeAg-positive phase (IR) was defined as $\mathrm{HBeAg}$ positivity, high levels of serum HBV DNA $(>1,000 \mathrm{IU} / \mathrm{mL})$, and ALT levels above upper normal limit $(>40$ $\mathrm{IU} / \mathrm{L})$. The low replicative (LR) state was defined as HBeAg negativity and HBV DNA levels of $<2,000 \mathrm{IU} / \mathrm{mL}$ with normal ALT levels ( $\leq 40 \mathrm{IU} / \mathrm{L}$ ), consistently and the HBeAg-negative CHB (ENH) was defined as HBeAg negativity and HBV DNA levels of $\geq 2,000 \mathrm{IU} / \mathrm{mL}$ with fluctuating levels of ALT.

Patients receiving oral NUCs at the time of HBsAg quantification were classified as follows: $\mathrm{HBeAg}$-positive $\mathrm{CHB}$ with virologic response $(\mathrm{E}+\mathrm{VR})$ was defined as $\mathrm{HBeAg}$ positivity and undetectable HBV DNA. HBeAg-positive CHB with partial virologic response $(\mathrm{E}+\mathrm{pVR})$ was defined as $\mathrm{HBeAg}$ positivity and decrease in HBV DNA of more than $1 \log _{10} \mathrm{IU} / \mathrm{mL}$ but detectable HBV DNA after at least 6 months of therapy. HBeAg-negative $\mathrm{CHB}$ with virologic response (E-VR) was defined as $\mathrm{HBeAg}$ negativity and undetectable HBV DNA. HBeAg-negative CHB with partial virologic response (E-pVR) was defined as $\mathrm{HBeAg}$ negativity and decrease in HBV DNA of more than $1 \log _{10} \mathrm{IU} /$ $\mathrm{mL}$ but detectable HBV DNA after at least 6 months of therapy.

\section{Quantitative HBsAg assay and HBV DNA quantification}

IRMA kits (RIAKEY; Shin Jin Medics, Goyang, Korea) were used for HBsAg quantification according to the manufacturer's instructions. Briefly, the samples were incubated with primary antibody-coated beads for 1 hour. The beads were then removed by washing 4 times in washing solution, and then treated with ${ }^{125}$ I-conjugated secondary antibody for 30 minutes. Next, radioactivity was measured in counts per minute (CPM) by using a gamma counter (Packard, Downers Grove, IL, USA). Serum HBsAg titers were determined by reading the CPM values off a standard curve. The test was considered positive when the serum $\mathrm{HBsAg}$ levels exceeded $0.1 \mathrm{IU} / \mathrm{mL}$ (detection range, 0.05 to $250 \mathrm{IU} / \mathrm{mL}$ ). When HBsAg levels exceeded the detection range, the test was repeated after diluting the sample. A COBAS Amplicor HBV Monitor test (Roche Molecular Systems, Pleasanton, CA, USA) was used to measure serum HBV DNA concentrations during the study period, which has a lower detection limit of 20 $\mathrm{IU} / \mathrm{mL}$. 


\section{Statistical analysis}

Statistical analysis was performed using SPSS version 17.0 (SPSS Inc., Chicago, IL, USA). Continuous variables were expressed as mean \pm standard deviation. Correlations between HBsAg titers and HBV DNA concentrations were analyzed using the Spearman's rho method. The mean values were compared using the Kruskal-Wallis test, while post hoc analysis was performed using the Mann-Whitney $U$ test. The trends in the distribution of HBsAg titers among different age groups were analyzed using the Jonckheere-Terpstra test. A p-value less than 0.05 was considered statistically significant.

\section{RESULTS}

\section{Baseline characteristics}

Overall, the data from 627 samples met the inclusion criteria. The baseline characteristics of all eligible patients belong-

Table 1. Baseline Characteristics of the Included Patients

\begin{tabular}{lcccccccccc}
\hline \multicolumn{1}{c}{ Characteristic } & Total & IT & IR & LR & ENH & E+VR & E+pVR & E-VR & E-pVR & p-value \\
\hline No. & 627 & 36 & 48 & 116 & 67 & 46 & 81 & 69 & 71 & - \\
Gender, male:female & $403: 224$ & $18: 18$ & $28: 20$ & $66: 50$ & $40: 27$ & $37: 9$ & $58: 23$ & $47: 22$ & $46: 25$ & 0.040 \\
Age, yr & $48.2 \pm 12.9$ & $45.9 \pm 13.4$ & $39.3 \pm 12.1$ & $49.4 \pm 13.3$ & $49.8 \pm 12.6$ & $46.5 \pm 12.6$ & $45.9 \pm 11.9$ & $55.8 \pm 10.1$ & $54.1 \pm 10.0$ & $<0.001$ \\
Cholesterol, mg/dL & $171.7 \pm 36.0$ & $174.9 \pm 28.8$ & $181.7 \pm 37.9$ & $176.5 \pm 41.0$ & $170.8 \pm 39.7$ & $172.0 \pm 33.2$ & $180.4 \pm 35.0$ & $159.6 \pm 37.3$ & $165.5 \pm 34.0$ & 0.009 \\
Protein, g/dL & $7.13 \pm 0.51$ & $6.95 \pm 0.40$ & $7.20 \pm 0.53$ & $7.12 \pm 0.44$ & $7.07 \pm 0.45$ & $7.24 \pm 0.38$ & $7.10 \pm 0.61$ & $7.12 \pm 0.66$ & $7.14 \pm 0.50$ & 0.119 \\
Albumin, g/dL & $4.02 \pm 0.40$ & $3.96 \pm 0.39$ & $4.01 \pm 0.34$ & $4.09 \pm 0.34$ & $3.94 \pm 0.37$ & $4.25 \pm 0.24$ & $4.07 \pm 0.30$ & $3.92 \pm 0.47$ & $3.89 \pm 0.47$ & $<0.001$ \\
Total bilirubin, mg/dL & $1.09 \pm 0.90$ & $0.81 \pm 0.34$ & $0.99 \pm 0.45$ & $0.94 \pm 0.57$ & $1.33 \pm 1.74$ & $1.04 \pm 0.45$ & $1.13 \pm 0.69$ & $1.43 \pm 1.10$ & $1.27 \pm 1.08$ & $<0.001$ \\
ALP, IU/L & $95.4 \pm 53.7$ & $87.2 \pm 32.4$ & $87.5 \pm 31.9$ & $87.6 \pm 48.5$ & $102.5 \pm 78.2$ & $85.3 \pm 43.7$ & $98.3 \pm 52.6$ & $105.4 \pm 47.0$ & $114.7 \pm 80.6$ & $<0.001$ \\
ALT, IU/L & $61.2 \pm 104.9$ & $23.6 \pm 9.3$ & $154.5 \pm 170.8$ & $32.8 \pm 30.5$ & $110.8 \pm 197.4$ & $23.8 \pm 12.0$ & $43.6 \pm 38.1$ & $29.7 \pm 14.3$ & $54.9 \pm 75.5$ & $<0.001$ \\
AST, IU/L & $57.5 \pm 89.1$ & $34.9 \pm 22.5$ & $107.9 \pm 94.1$ & $42.5 \pm 66.4$ & $101.3 \pm 188.0$ & $27.2 \pm 14.9$ & $39.0 \pm 26.6$ & $35.7 \pm 12.5$ & $58.8 \pm 78.2$ & $<0.001$ \\
LC & $253(40.4)$ & $11(30.6)$ & $8(16.7)$ & $36(31.0)$ & $30(44.8)$ & $9(19.6)$ & $30(37.0)$ & $49(71.0)$ & $54(76.1)$ & $<0.001$ \\
HCC & $93(14.8)$ & $1(2.8)$ & 0 & $18(15.5)$ & $9(13.4)$ & $4(8.7)$ & $10(12.3)$ & $25(36.2)$ & $18(25.4)$ & $<0.001$
\end{tabular}

Data are presented as mean \pm SD or number $(\%)$.

IT, immunotolerant; IR, immunoreactive; LR, low-replicative; ENH, HBeAg-negative CHB; E+VR, HBeAg-positive CHB with virologic response; $\mathrm{E}+\mathrm{pVR}, \mathrm{HBeAg}$-positive $\mathrm{CHB}$ with partial virologic response; E-VR, HBeAg-negative CHB with virologic response; E-pVR, HBeAg-negative CHB with partial virologic response; ALP, alkaline phosphatase; ALT, alanine aminotransferase; AST, aspartate aminotransferase; LC, liver cirrhosis; HCC, hepatocellular carcinoma.

A

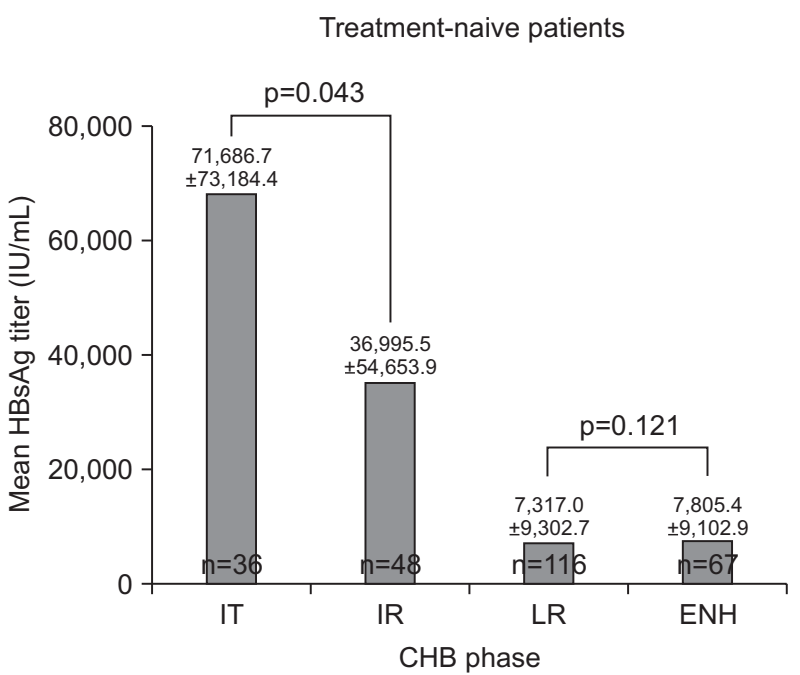

B

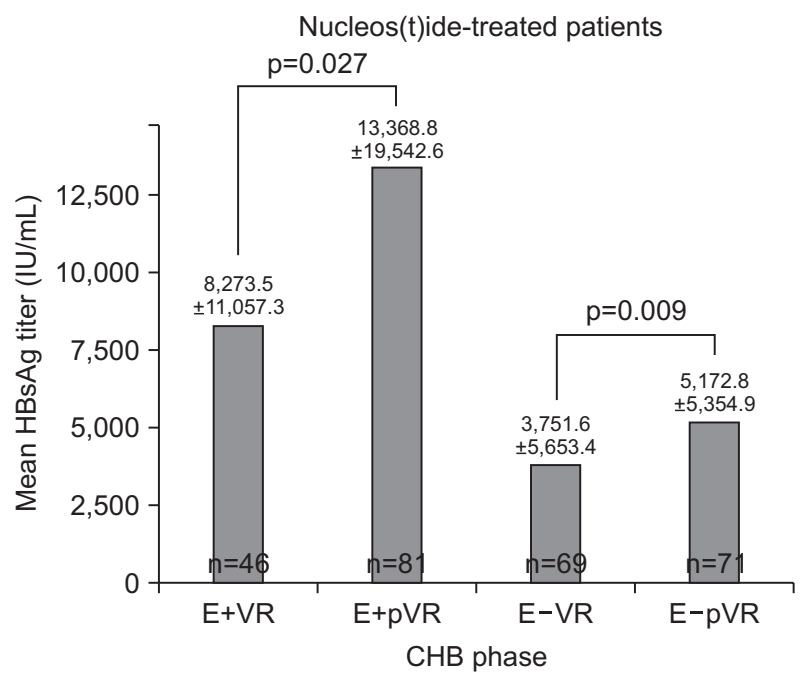

Fig. 1. Comparison of mean hepatitis B surface antigen (HBsAg) titers among the different phases of chronic hepatitis B (CHB) and the different treatment outcome groups. (A) Treatment-naive patients; (B) nucleos(t)ide-treated patients.

IT, immunotolerant phase; IR, immunoreactive hepatitis B e antigen (HBeAg)-positive phase; LR, low-replicative phase; ENH, HBeAg-negative $\mathrm{CHB}$; E+VR, HBeAg-positive CHB with virologic response; E+pVR, HBeAg-positive CHB with partial virologic response; E-VR, HBeAg-negative CHB with virologic response; E-pVR, HBeAg-negative CHB with partial virologic response. 
ing to the different phases of $\mathrm{CHB}$ and the different treatment outcome groups are presented in Table 1. All patients were of Asian ethnicity, and a greater proportion (64.3\%) of the total subjects was male. Among the 627 samples, 93 paired samples from the patients receiving interferon treatment $(n=34)$, those with virologic breakthrough during the NUC treatment $(n=4)$, or those who discontinued NUC treatment $(n=55)$ were excluded from classification into the different phases of CHB. Thus, 534 paired samples were divided into eight different groups. Among the 267 samples obtained from the treatment-naive patients, 36 were in the IT phase; 48, in IR; 116, in LR; and 67, in ENH. The remaining 267 samples obtained from the NUC-treated patients were categorized as follows: 46 were in the E+VR group; 81, in $\mathrm{E}+\mathrm{pVR}$; 69, in E-VR+; and 71, in E-pVR.

\section{Comparison of HBsAg titers among different phases of CHB and different treatment outcome groups}

The mean HBsAg titers significantly differed among eight
A

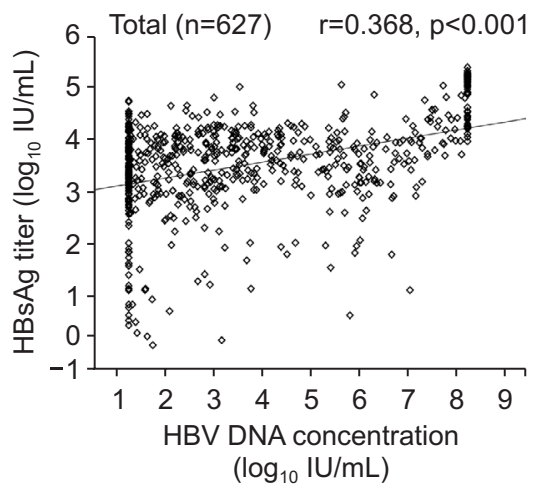

D

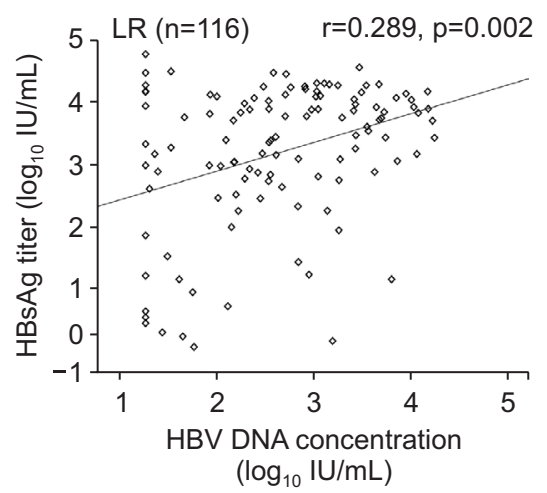

G

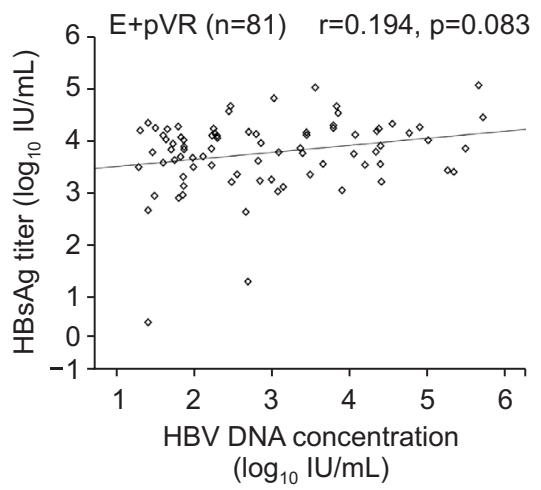

B

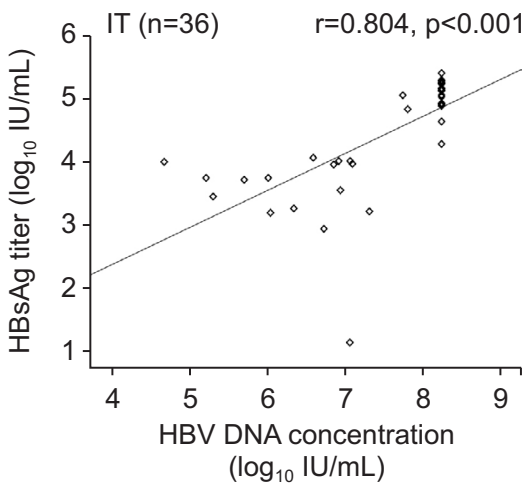

E

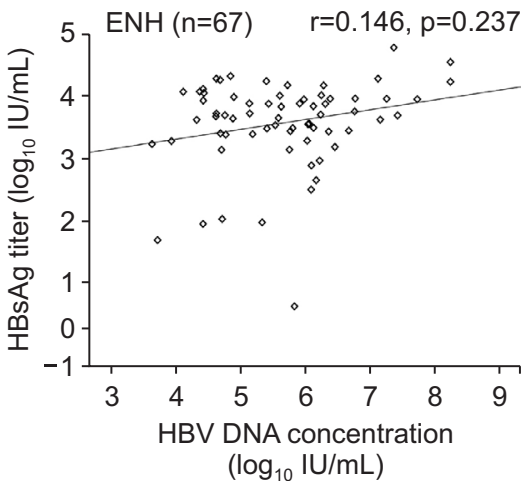

$\mathrm{H}$

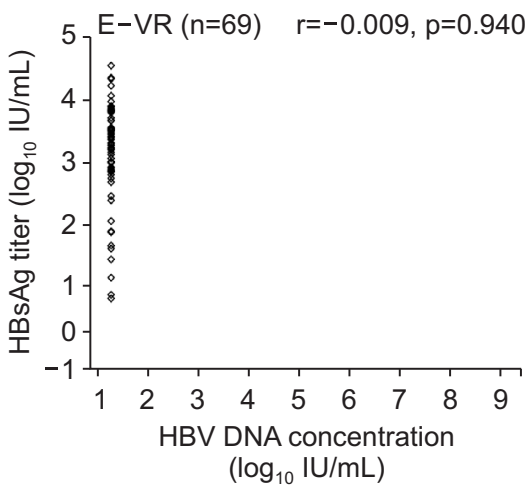

C

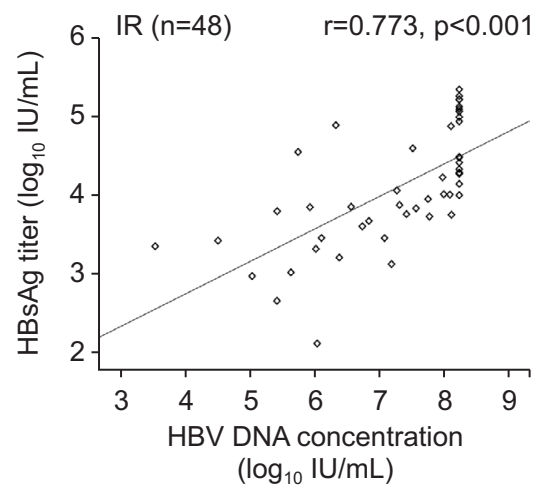

F

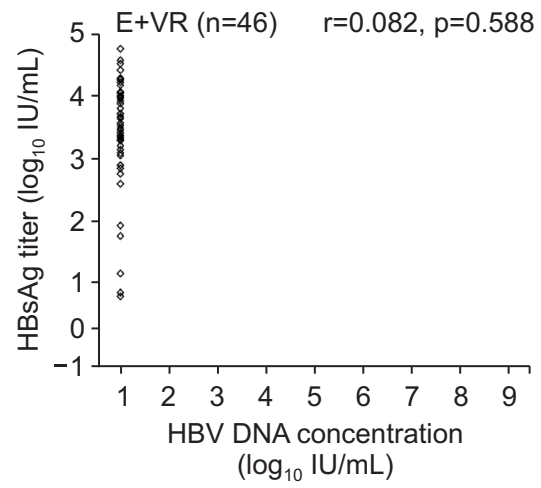

I

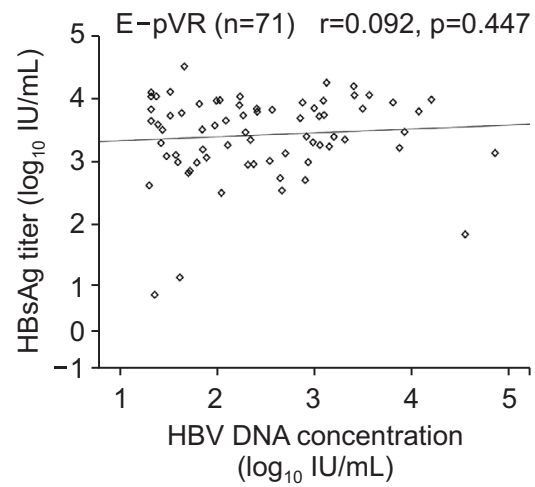

Fig. 2. Correlations between serum hepatitis B surface antigen (HBsAg) titers and hepatitis B virus (HBV) DNA concentrations in the different phases of chronic hepatitis B (CHB). (A) Total population; (B) immunotolerant phase (IT); (C) immunoreactive hepatitis B e antigen (HBeAg)-positive phase (IR); (D) low-replicative phase (LR); (E) HBeAg-negative CHB (ENH); (F) HBeAg-positive CHB with virologic response (E+VR); (G) HBeAgpositive $\mathrm{CHB}$ with partial virologic response $(\mathrm{E}+\mathrm{pVR})$; (H) HBeAg-negative $\mathrm{CHB}$ with virologic response (E-VR); (I) HBeAg-negative $\mathrm{CHB}$ with partial virologic response (E-pVR). 
subgroups, and the titer values per phase for the treatmentnaive patients averaged 71,686.7 IU/mL in IT, 36,995.5 IU/mL in $\mathrm{IR}, 7,317.0 \mathrm{IU} / \mathrm{mL}$ in $\mathrm{LR}$, and 7,805.4 IU/mL in ENH (Fig. 1A). The mean HBsAg titer was significantly higher in IT than in IR ( $p=0.043$ ) but, the difference in the mean HBsAg titers between LR and ENH was not statistically significant $(p=0.121)$. The mean HBsAg titers per phase for the NUC-treated patients were 8,273.5 IU/mL in E+VR, 13,368.8 IU/mL in E+pVR, 3,751.6 IU/ $\mathrm{mL}$ in E-VR, and 5,172.8 IU/mL in E-pVR (Fig. 1B). The mean HBsAg titer was significantly higher in $E+p V R$ than in $E+V R$ $(p=0.027)$, and was also significantly higher in $E-p V R$ than in E-VR ( $p=0.009$ ) The mean HBsAg titer was significantly higher in IT plus IR than in LR plus ENH $(\mathrm{p}<0.001)$, and was significantly higher in the HBeAg-positive group than in the HBeAgnegative group, irrespective of the use of NUCs $(p<0.001)$.

\section{Correlation between serum HBsAg titers and HBV DNA concentrations}

Correlations between HBsAg titers and HBV DNA concentrations are shown in Fig. 2. A modest correlation was observed in the IT and IR phases ( $r=0.804, p<0.001$; and $r=0.773, p<0.001)$. In addition, a poor correlation was observed in the LR phase $(\mathrm{r}=0.289, \mathrm{p}=0.002)$. However, no significant correlation was observed in ENH ( $r=0.146, p=0.237), E+V R(r=0.082, p=0.588)$, $\mathrm{E}+\mathrm{pVR}(\mathrm{r}=0.194, \mathrm{p}=0.083), \mathrm{E}-\mathrm{VR}(\mathrm{r}=-0.009, \mathrm{p}=0.940)$, or $\mathrm{E}-\mathrm{pVR}$ $(\mathrm{r}=0.092, \mathrm{p}=0.447)$.

\section{Distribution of HBsAg titers across 10-year age strata and different stages of chronic liver disease}

The mean serum HBsAg titers tended to be significantly higher in younger age groups than in older age groups. The mean serum HBsAg titers tended to gradually decrease as the 10-year age stratum increased ( $p$ for trend<0.001) (Fig. 3). The mean HBsAg titers significantly differed between the patients with and without cirrhosis. The mean HBsAg titer was nearly 5 times

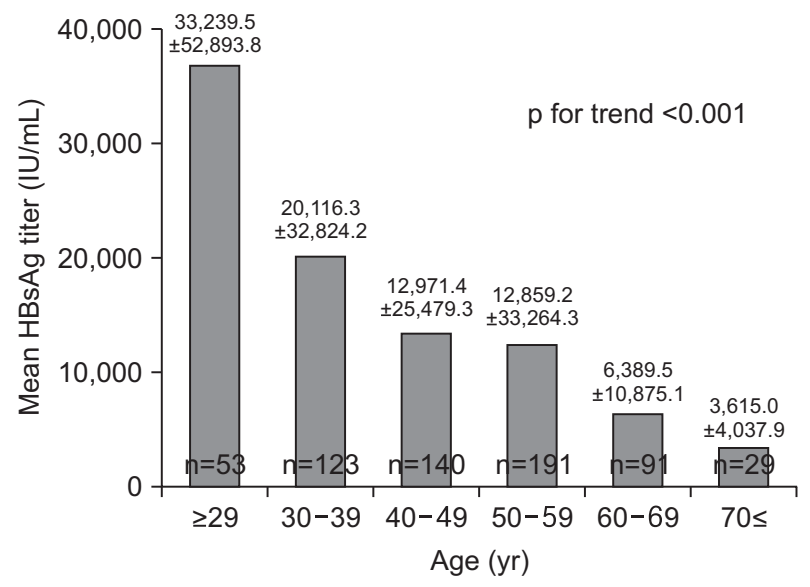

Fig. 3. Distribution of mean hepatitis B surface antigen (HBsAg) titers in 10-year age strata. higher in the noncirrhosis group than in the cirrhosis group $(21,517.6 \mathrm{IU} / \mathrm{mL}$ vs 4,532.8 IU/mL, p<0.001) (Fig. 4), and was significantly higher in the patients without HCC than in those with HCC $(16,615.0 \mathrm{IU} / \mathrm{mL}$ vs 3,461.8 IU/mL, p<0.001) (Fig. 5). To control for the confounding effect of age on the HBsAg titers of those with liver cirrhosis and HCC, we performed subgroup analysis by stratifying patients' age into $<60$ and $\geq 60$. Of those who were younger than 60 year-old, the mean HBsAg titer was significantly higher in the noncirrhosis group than in the cirrhosis group $(22,996.7 \mathrm{IU} / \mathrm{mL}$ vs 4,886.18 $\mathrm{IU} / \mathrm{mL}, \mathrm{p}<0.001)$ and was also significantly higher in the non-HCC group than in the HCC group (18,371.3 vs 3,443.7, p<0.001). Similarly, of those who were older than 60 year-old, the mean HBsAg titer was significantly higher in noncirrhotic patients than in cirrhotic ones $(9,504.3 \mathrm{IU} / \mathrm{mL}$ vs 3,754.4 IU/mL, p=0.019) and was higher in the patients without HCC than in those with HCC, though it was not statistically significant $(6,793.0$ vs $3,645.6, p=0.12)$.

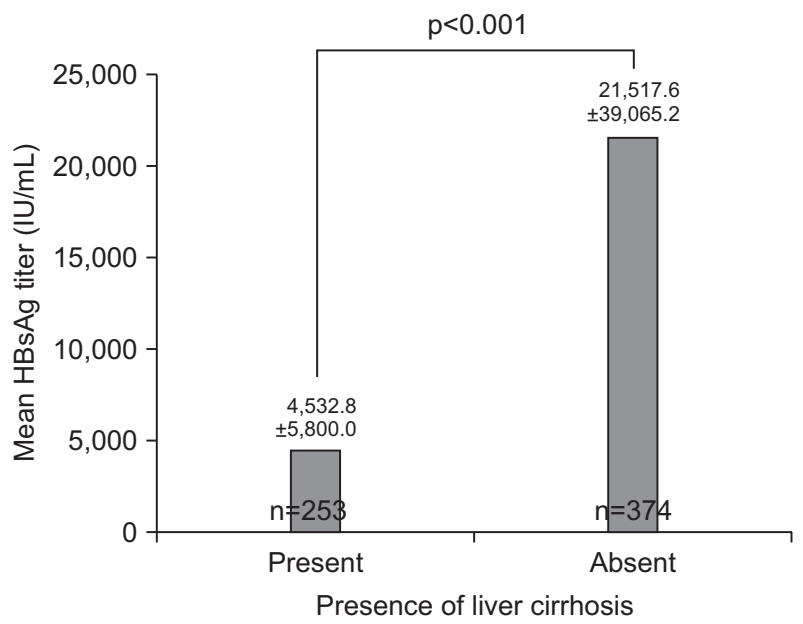

Fig. 4. Comparison of mean hepatitis B surface antigen (HBsAg) titers between patients with and without liver cirrhosis.

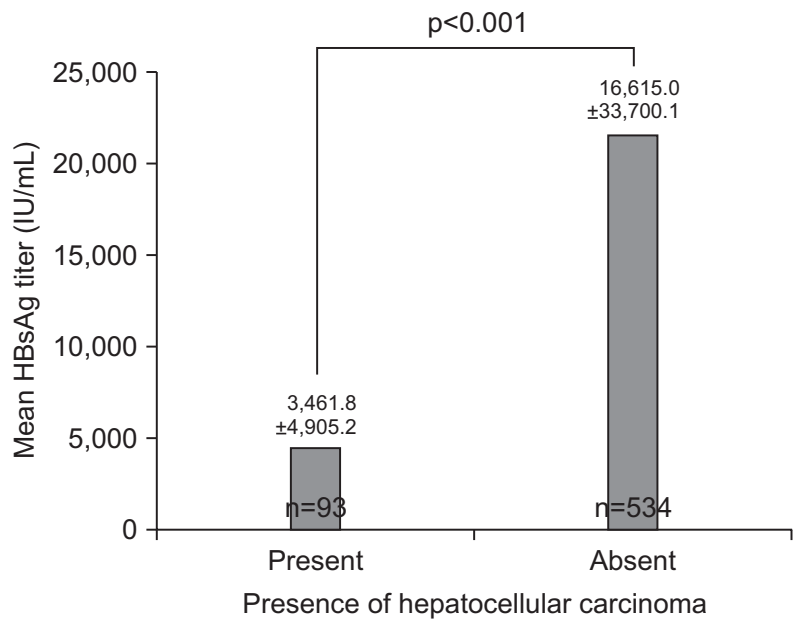

Fig. 5. Comparison of mean hepatitis B surface antigen (HBsAg) titers between patients with and without hepatocellular carcinoma. 


\section{DISCUSSION}

This study aimed to evaluate the differences of serum HBsAg titers across different phases of $\mathrm{CHB}$, and to reveal correlations between HBsAg titers and HBV DNA concentrations by using IRMA. All study subjects were Korean and of Asian ethnicity, which predominantly harbored genotype $\mathrm{C}$ of HBV. ${ }^{23,24}$ Previous studies have demonstrated correlations between HBsAg titers and HBV DNA concentrations by using CMIA, , 12,13,15-18 and IRMA has shown a performance similar to CMIA with regard to HBsAg quantification. ${ }^{19}$ To the best of our knowledge, this is the first to analyze the correlations between HBsAg titers and HBV DNA concentrations across different phases of CHB by using IRMA.

In both IT and IR phases, a modest correlation was observed between HBsAg titers and HBV DNA concentrations; however, it was not reproduced in either LR or ENH phases, or in the NUC-treated group. Our results were similar to those of previous studies; a modest correlation was shown between HBsAg titers and HBV DNA concentrations in HBeAg-positive patients. However, this was not true for HBeAg-negative patients. ${ }^{16,18}$

Serum HBsAg exists as either mature virions or smaller noninfectious subviral particles. ${ }^{25,26}$ In the IT phase, HBV can most freely and actively replicate and spread, without inducing imminent immune responses. ${ }^{27}$ In this phase, most serum HBsAg particles may be the components of full virions, which accounts for a positive correlation between HBV DNA concentrations and HBsAg titers in the IT phase. $^{28,29}$

In the IR phase, both HBV DNA in serum as part of the virion and intrahepatic cccDNA are simultaneously affected by immune responses. ${ }^{30,31}$ Therefore, the production of serum HBsAg, HBV DNA, and intrahepatic cccDNA may decline at the same time, and a positive correlation between HBV DNA concentrations and $\mathrm{HBsAg}$ titers is maintained during immune-mediated injury. In the present study, the mean HBsAg titer was lower in the IR phase than in the IT phase, which may be attributed to immune clearance.

In the LR phase, immunological control of HBV infection commences with the inhibition of viral replication and reduction of serum HBV DNA concentrations. ${ }^{31-33}$ Spontaneous immune reactions also induce reduction of virions and their HBsAg particles. ${ }^{16,34,35}$ However, the immune reaction is not robust enough to clear infected hepatocytes of cccDNA and to reduce the production of subviral particles. That might explain the discrepancy between serum HBV DNA concentrations and HBsAg titers during the LR phase.

In the ENH phase, HBV replication reactivation results in the increased production of virions; immune activation also simultaneously mediates the inhibition of viral replication. ${ }^{36,37}$ Therefore, virion assembly might occur to some degree in the ENH phase, although not as much as in the IR phase. Moreover, vast amounts of serum HBsAg detected in the ENH phase may be the components of subviral particles, but not of full virions. This hypothesis is supported by a previous study, which showed a poor correlation between HBsAg titers and cccDNA concentrations in $\mathrm{HBeAg}$-negative patients. ${ }^{18}$

Previous studies showed that HBeAg-positive patients possess higher HBsAg titers than HBeAg-negative patients do, which is in line with our results. ${ }^{15-18}$ Spontaneous seroconversion of HBsAg during the long-term follow-up period is not uncommon, and the seroconversion rate increases as the follow-up duration is extended. ${ }^{34,38,39}$ This might explain our results, wherein the HBsAg titers tended to decrease with increasing age. It can be assumed that, with longer disease duration, infected hepatocytes are gradually removed by the immune system. The mean $\mathrm{HBsAg}$ titer was significantly lower in patients with cirrhosis and HCC than in those without cirrhosis and HCC. It is well acknowledged that higher HBsAg titers at baseline are related with the higher incidence of liver cirrhosis or HCC during the followup period. ${ }^{40,41}$ However, we did not retrieve the HBsAg titers at baseline in our study but compare the HBsAg titers of patients who already had liver cirrhosis or HCC with the HBsAg titers of those who did not have liver cirrhosis or HCC yet. We presumed that longer disease duration or chronic hepatocellular damage might cause the decrement of absolute cccDNA, the intrahepatic burden of HBV; however, this remains unproven. A tendency toward lower HBsAg titers in patients with advanced age, cirrhosis, and HCC might provide some guidelines to predict clinical outcomes. However, it is unclear whether discrimination based on optimal cutoff values of HBsAg titers might be useful to predict spontaneous seroconversion and progression to cirrhosis and HCC.

In the present study, we compared HBsAg titers between treatment-naive patients and those receiving oral NUCs. Recent data suggest a potential role for HBsAg quantification in ontreatment monitoring during pegylated interferon $\alpha$ therapy. ${ }^{42-44}$ However, there has been a paucity of data on the clinical utility of $\mathrm{HBsAg}$ quantification to predict virologic responses during oral NUC therapies. The recent retrospective study reported that the baseline $\mathrm{HBsAg}$ titer of $<1,000 \mathrm{IU} / \mathrm{mL}$ and on-treatment reduction of $\mathrm{HBsAg}$ titer $>0.166 \log \mathrm{IU} / \mathrm{mL} / \mathrm{yr}$ were good predictors of HBsAg seroclearance during NUC treatment. ${ }^{45}$ However, further studies involving longitudinal analysis of $\mathrm{HBsAg}$ titers along with long-term NUC treatment are needed to determine optimal cutoff values, which are associated with viral clearance.

Our study has several limitations owing to its retrospective nature and cross-sectional design. The definition of the different phases of CHB was mainly based on laboratory findings. Therefore, this might have inevitably resulted in misclassification bias. However, in the present study, differential analysis was done using IRMA for HBsAg quantification in patients who were either treatment-naive or treated with NUC. In particular, for the treatment-naive ones, correlation analysis between HBsAg and HBV DNA results was performed across different 
phases of CHB.

Although the direct comparison betweem CMIA and IRMA was not feasible in our study, the degree of correlation between HBsAg titers and HBV DNA concentrations in our study was stronger than in previous studies or at least similar to the results from those in the different phases of $\mathrm{CHB} .{ }^{15,17}$ In our study, the correlation coefficient in the IT phase was 0.804 which was much higher than the results from previous studies $(0.300$ and 0.340). In the IC phase, the correlation coefficient was 0.773 in our study; however, previous studies showed 0.770 and 0.110 of the correlation coefficient, respectively. On the other hand, there has been only one study which has investigated the correlation between HBsAg titers and HBV DNA concentrations in patients with liver cirrhosis or HCC. ${ }^{13}$ Among the patients with liver cirrhosis, the correlation coefficient was $0.383(\mathrm{p}<0.001)$ in our study; however, it was $0.156(\mathrm{p}=0.095)$ in the previous study. Among those with HCC, the correlation coefficient was 0.349 $(\mathrm{p}<0.001)$ in our study; however, it was $0.328(\mathrm{p}=0.002)$ in the previous study.

In conclusion, HBsAg titers varied across different phases of CHB in treatment-naive patients. In addition, HBsAg titers were significantly lower in patients who were advanced in age, receiving NUCs, or had cirrhosis or HCC. Quantitative HBsAg titers measured using IRMA showed a positive correlation with viral load in HBeAg-positive patients. These results imply some potential roles for HBsAg quantification in monitoring the natural course and clinical outcomes in patients with CHB. Further studies are warranted to elucidate a potential role for $\mathrm{HBsAg}$ quantification as a surrogate marker in assessing disease activity and monitoring treatment responses.

\section{CONFLICTS OF INTEREST}

No potential conflict of interest relevant to this article was reported.

\section{REFERENCES}

1. Lavanchy D. Hepatitis B virus epidemiology, disease burden, treatment, and current and emerging prevention and control measures. J Viral Hepat 2004;11:97-107.

2. Lok AS, McMahon BJ. Chronic hepatitis B. Hepatology 2007;45: 507-539.

3. Liaw YF, Sung JJ, Chow WC, et al. Lamivudine for patients with chronic hepatitis B and advanced liver disease. N Engl J Med 2004;351:1521-1531.

4. Lee CI, Kwon SY, Kim JH, et al. Efficacy and safety of tenofovirbased rescue therapy for chronic hepatitis B patients with previous nucleo(s/t)ide treatment failure. Gut Liver 2014;8:64-69.

5. Kwon DH, Kim IH, Choung BS, et al. Continuous long-term entecavir therapy in naive chronic hepatitis B patients showing partial virologic response. Gut Liver 2013;7:712-718.
6. Idilman R, Cinar K, Seven G, et al. Hepatitis B surface antigen seroconversion is associated with favourable long-term clinical outcomes during lamivudine treatment in HBeAg-negative chronic hepatitis B patients. J Viral Hepat 2012;19:220-226.

7. European Association for the Study of the Liver. EASL clinical practice guidelines: management of chronic hepatitis B. J Hepatol 2009;50:227-242.

8. Wursthorn K, Lutgehetmann M, Dandri M, et al. Peginterferon alpha-2b plus adefovir induce strong cccDNA decline and HBsAg reduction in patients with chronic hepatitis B. Hepatology 2006;44:675-684.

9. Volz T, Lutgehetmann M, Wachtler P, et al. Impaired intrahepatic hepatitis B virus productivity contributes to low viremia in most HBeAg-negative patients. Gastroenterology 2007;133:843-852.

10. Chan HL, Wong GL, Chim AM, Chan HY, Chu SH, Wong VW. Prediction of off-treatment response to lamivudine by serum hepatitis B surface antigen quantification in hepatitis B e antigen-negative patients. Antivir Ther 2011;16:1249-1257.

11. Liang Y, Jiang J, Su M, et al. Predictors of relapse in chronic hepatitis B after discontinuation of anti-viral therapy. Aliment Pharmacol Ther 2011;34:344-352.

12. Ganji A, Esmaeilzadeh A, Ghafarzadegan K, Helalat H, Rafatpanah $\mathrm{H}$, Mokhtarifar A. Correlation between HBsAg quantitative assay results and HBV DNA levels in chronic HBV. Hepat Mon 2011;11: 342-345.

13. Lee JH, Kim SJ, Ahn SH, Lee J, Park Y, Kim HS. Correlation between quantitative serum HBsAg and HBV DNA test in Korean patients who showed high level of HBsAg. J Clin Pathol 2010;63: 1027-1031.

14. Moucari R, Marcellin P. Quantification of hepatitis B surface antigen: a new concept for the management of chronic hepatitis B. Liver Int 2011;31 Suppl 1:122-128.

15. Nguyen T, Thompson AJ, Bowden S, et al. Hepatitis B surface antigen levels during the natural history of chronic hepatitis $\mathrm{B}$ : a perspective on Asia. J Hepatol 2010;52:508-513.

16. Chan HL, Wong VW, Wong GL, Tse CH, Chan HY, Sung JJ. A longitudinal study on the natural history of serum hepatitis B surface antigen changes in chronic hepatitis B. Hepatology 2010;52:12321241.

17. Jaroszewicz J, Calle Serrano B, Wursthorn K, et al. Hepatitis B surface antigen (HBsAg) levels in the natural history of hepatitis $B$ virus (HBV)-infection: a European perspective. J Hepatol 2010;52: 514-522.

18. Thompson AJ, Nguyen T, Iser D, et al. Serum hepatitis B surface antigen and hepatitis B e antigen titers: disease phase influences correlation with viral load and intrahepatic hepatitis B virus markers. Hepatology 2010;51:1933-1944.

19. Kwon HW, Lee HY, Kim SG, et al. Quantitative measurement of serum hepatitis B surface antigen using an immunoradiometric assay in chronic hepatitis B. Nucl Med Mol Imaging 2011;45:1520.

20. Kim H, Oh EJ, Kang MS, Kim SH, Park YJ. Comparison of the Ab- 
bott Architect i2000 assay, the Roche Modular Analytics E170 assay, and an immunoradiometric assay for serum hepatitis B virus markers. Ann Clin Lab Sci 2007;37:256-259.

21. Wursthorn K, Jaroszewicz J, Zacher BJ, et al. Correlation between the Elecsys HBsAg II assay and the Architect assay for the quantification of hepatitis B surface antigen (HBsAg) in the serum. J Clin Virol 2011;50:292-296.

22. European Association for the Study of the Liver. EASL clinical practice guidelines: management of chronic hepatitis B virus infection. J Hepatol 2012;57:167-185.

23. Cho JH, Yoon KH, Lee KE, et al. Distribution of hepatitis B virus genotypes in Korea. Korean J Hepatol 2009;15:140-147.

24. Song BC, Cui XJ, Kim H. Hepatitis B virus genotypes in Korea: an endemic area of hepatitis B virus infection. Intervirology 2005;48: 133-137.

25. Lee JM, Ahn SH. Quantification of HBsAg: basic virology for clinical practice. World J Gastroenterol 2011;17:283-289.

26. Ganem D, Prince AM. Hepatitis B virus infection: natural history and clinical consequences. N Engl J Med 2004;350:1118-1129.

27. Ribeiro RM, Lo A, Perelson AS. Dynamics of hepatitis B virus infection. Microbes Infect 2002;4:829-835.

28. Dienes HP, Gerlich WH, Wörsdörfer M, et al. Hepatic expression patterns of the large and middle hepatitis $\mathrm{B}$ virus surface proteins in viremic and nonviremic chronic hepatitis B. Gastroenterology 1990;98:1017-1023.

29. Lau JY, Bain VG, Davies SE, Alexander GJ, Williams R. Export of intracellular HBsAg in chronic hepatitis B virus infection is related to viral replication. Hepatology 1991;14:416-421.

30. Thimme R, Wieland S, Steiger C, et al. CD8(+) T cells mediate viral clearance and disease pathogenesis during acute hepatitis B virus infection. J Virol 2003;77:68-76.

31. Liaw YF. Hepatitis flares and hepatitis B e antigen seroconversion: implication in anti-hepatitis B virus therapy. J Gastroenterol Hepatol 2003;18:246-252.

32. Chu CM, Yeh CT, Lee CS, Sheen IS, Liaw YF. Precore stop mutant in HBeAg-positive patients with chronic hepatitis B: clinical characteristics and correlation with the course of HBeAg-to-anti-HBe seroconversion. J Clin Microbiol 2002;40:16-21.

33. Yuen MF, Sablon E, Yuan HJ, et al. Relationship between the development of precore and core promoter mutations and hepatitis $\mathrm{B}$ e antigen seroconversion in patients with chronic hepatitis B virus. J Infect Dis 2002;186:1335-1338.

34. Liaw YF, Sheen IS, Chen TJ, Chu CM, Pao CC. Incidence, determi- nants and significance of delayed clearance of serum HBsAg in chronic hepatitis B virus infection: a prospective study. Hepatology 1991;13:627-631.

35. Chan HL, Wong VW, Tse AM, et al. Serum hepatitis B surface antigen quantitation can reflect hepatitis B virus in the liver and predict treatment response. Clin Gastroenterol Hepatol 2007;5:14621468.

36. Fattovich G, Olivari N, Pasino M, D’Onofrio M, Martone E, Donato F. Long-term outcome of chronic hepatitis B in Caucasian patients: mortality after 25 years. Gut 2008;57:84-90.

37. Hsu YS, Chien RN, Yeh CT, et al. Long-term outcome after spontaneous $\mathrm{HBeAg}$ seroconversion in patients with chronic hepatitis $\mathrm{B}$. Hepatology 2002;35:1522-1527.

38. Chu CM, Liaw YF. HBsAg seroclearance in asymptomatic carriers of high endemic areas: appreciably high rates during a long-term follow-up. Hepatology 2007;45:1187-1192.

39. Manno M, Cammà C, Schepis F, et al. Natural history of chronic HBV carriers in northern Italy: morbidity and mortality after 30 years. Gastroenterology 2004;127:756-763.

40. Tseng TC, Liu CJ, Yang HC, et al. High levels of hepatitis B surface antigen increase risk of hepatocellular carcinoma in patients with low HBV load. Gastroenterology 2012;142:1140-1149.e3.

41. Tseng TC, Liu CJ, Yang HC, et al. Serum hepatitis B surface antigen levels help predict disease progression in patients with low hepatitis B virus loads. Hepatology 2013;57:441-450.

42. Brunetto MR, Moriconi F, Bonino F, et al. Hepatitis B virus surface antigen levels: a guide to sustained response to peginterferon alfa2a in HBeAg-negative chronic hepatitis B. Hepatology 2009;49: $1141-1150$

43. Moucari R, Mackiewicz V, Lada O, et al. Early serum HBsAg drop: a strong predictor of sustained virological response to pegylated interferon alfa-2a in HBeAg-negative patients. Hepatology 2009; 49:1151-1157.

44. Kwon JH, Kim YS, Kim SG, et al. The efficacy and safety of peginterferon-alfa-2a in Korean patients with chronic hepatitis B: a multicenter study conducted in a real clinical setting. Gut Liver 2013;7:197-205.

45. Seto WK, Wong DK, Fung J, Huang FY, Lai CL, Yuen MF. Reduction of hepatitis B surface antigen levels and hepatitis B surface antigen seroclearance in chronic hepatitis B patients receiving 10 years of nucleoside analogue therapy. Hepatology 2013;58:923931. 